Original Article

\title{
Correlation of prostate volume with 'International Prostate Symptom Score' and 'Benign Prostatic Hyperplasia-Impact Index' in benign prostatic hyperplasia
}

\author{
Gnyawali $D^{1}$, Sharma $\mathbf{U}^{2}$ \\ Correspondence: Diwas Gnyawali, Email: diwasgnyawali@gmail.com,
}

\begin{abstract}
Introduction: Benign prostatic Hyperplasia is a common disorder and cause of morbidity in the ageing men. The evaluation symptoms and the bother associated with it are important for management. International Prostate Symptom Score (IPSS), Quality of life (QOL) and Benign Prostatic Hyperplasia Impact Index (BII) are practiced to quantify the severity of the disease. The size of prostate gland does not correlate with lower urinary tract symptoms. Correlation among above scoring is also not clear. Aim of the study is to evaluate correlation of prostate volume with International Prostate Symptom Score, Benign Prostatic Hyperplasia Impact Index and prostate size.

Methods: Prospective study. Ninety-eight patients were included. Patients were assessed preoperatively with the International Prostate Symptom Score, Benign Prostatic Hyperplasia Impact Index and prostate volumes by trans abdominal ultrasound.

Results: The mean age was $66.7 \pm 7.3$ years $(50-84)$ the mean IPSS, QOL, BII and prostate volumes were $23.6 \pm 6.0,5.1 \pm 0.9,7.1 \pm 2.4$ and $47.5 \pm 16.63$ respectively. There was positive correlation between the IPSS and BII, IPSS and QOL and BII and QOL ( $\mathrm{r}_{\mathrm{s}}=0.89,0.585$ and 0.530 respectively) and no correlation between IPSS and BII with prostatic weight. ( $\mathrm{r}_{\mathrm{s}}=-0.04$ and -0.07 respectively).

Conclusion: Management of the benign prostate hyperplasia should be considered on the bother symptoms and not on the size of the prostate.
\end{abstract}

Key words: Benign prostatic hyperplasia; International Prostate Symptom Score; Benign Prostatic Hyperplasia Impact Index; Prostate weight

\section{Introduction}

Benign prostatic hyperplasia (BPH) is a major cause of morbidity in the ageing men and increases with age. ${ }^{1}$ It cause disturbed voiding in men, the symptoms of which are collectively referred to as lower urinary tract symptoms (LUTS).

The AUA-7 symptom index has been adopted by the World Health Organization (WHO) as the International Prostate Symptom Score (IPSS) after the addition of one diseasespecific quality of life question as a means of assessing the global impact of BPH on quality of life. ${ }^{2}$ On validation, the AUA-7 index has been shown to have excellent test-retest reliability and is internally consistent. ${ }^{3}$ Similarly, the Benign Prostatic Hyperplasia Impact Index (BII) was developed as a set of ratings to assess the impact the symptoms of BPH on patient's health over the past month. The evaluation of prostatic size before intervention is also important.

There have been studies that studied relationship of prostate size with IPSS and IPSS with BII. But the study about relationship of BII with prostate size was not found. Aim of this study is to determine the relationship among the prostate volume, IPSS and BII. 


\section{Methods}

This was a prospective study conducted in the urology unit, Department of the Tribhuvan University Teaching Hospital (TUTH), Kathmandu, Nepal. The study was conducted over period of 8 months and Informed consent was taken from the patient or their relatives. Approval for the study was taken from Intuitional review board of Institute of Medicine. Nighty-eight patients admitted for operation of BPH were included in the study. Patients with more than one month of foley's catheterization, carcinoma of prostate, associated bladder calculus, bladder carcinoma, neurogenic Bladder and urethral stricture were excluded from the study.

These patients were assessed for severity of symptom severity by calculating the IPSS \& QOL and BII. Prostatic weight was calculated by transabdominal ultrasonography. Other tests were done as indicated to rule out other disease processes suggested by the clinical history or the initial tests.

The data were analyzed using the Statistical program for social sciences (SPSS) for mac (release 21.0). Correlation analysis and the paired t-test were done for statistical analysis. A $P$-value of $<0.05$ was taken as statistically significant.

\section{Results}

One Hundred and twenty-seven patients were admitted with the diagnosis of benign enlargement of prostate during the study period and out of them 98 patients were enrolled for the study after meeting the inclusion and exclusion criteria. The mean age of the patients were $66.7 \pm 7.3$ years (range 50 to 84 ).

Prostatic weight, as determined by transabdominal ultrasound examination ranged from 20 to $108 \mathrm{gm}$.; with a resultant mean weight of $47.54- \pm 18.6 \mathrm{~g}$. Most of the patients had prostate volumes in excess of $40 \mathrm{~g}$.

\section{Table 1: Frequency distribution IPSS}

\begin{tabular}{lll} 
Symptom score & No. of patients & Percent \\
$\leq 7$ & 0 & 0 \\
$8-19$ & 24 & $25.5 \%$ \\
$20-35$ & 74 & $74.5 \%$ \\
Total & 98 & $100 \%$ \\
\hline
\end{tabular}

In this study, the mean IPSS score was $23.6 \pm 6.07$ (range: 12 to 35 ), and mean quality of life was $5.1 \pm 0.91$ (range: 2 to 6 ).
Table 2. Descriptive statistics showing mean values and range of symptom scores

\begin{tabular}{lll}
$\begin{array}{l}\text { Symptom } \\
\text { scores }\end{array}$ & $\begin{array}{l}\text { Patient } \\
\text { number }\end{array}$ & Mean \pm SD (range) \\
\hline IPSS & 98 & $23.6 \pm 6.07(12$ to 35$)$ \\
QOL & 98 & $5.1 \pm 0.91(2$ to 6$)$ \\
BII & 98 & $7.14 \pm 2.42(2$ to 12$)$
\end{tabular}

\section{Correlations}

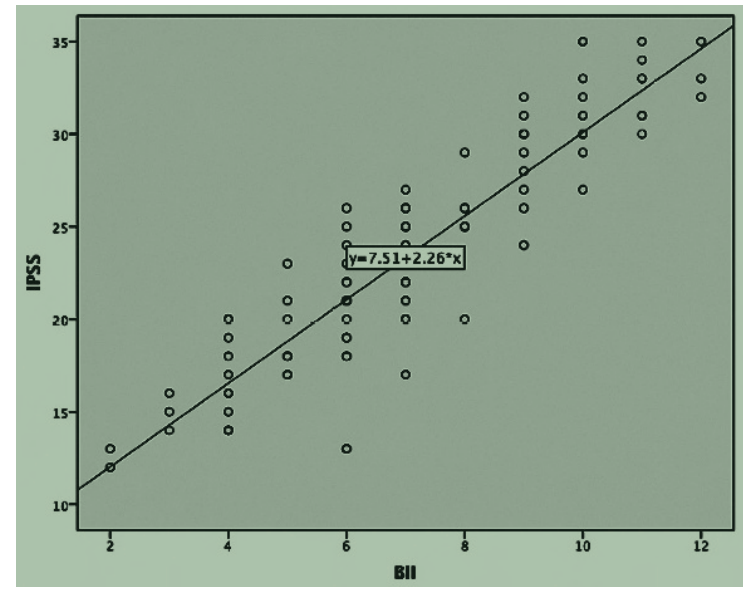

Figure 1. Scatter diagram showing correlation between IPSS and BPH II

Spearman's rho Correlation Coefficient 0.899 (P value $<0.001$ )

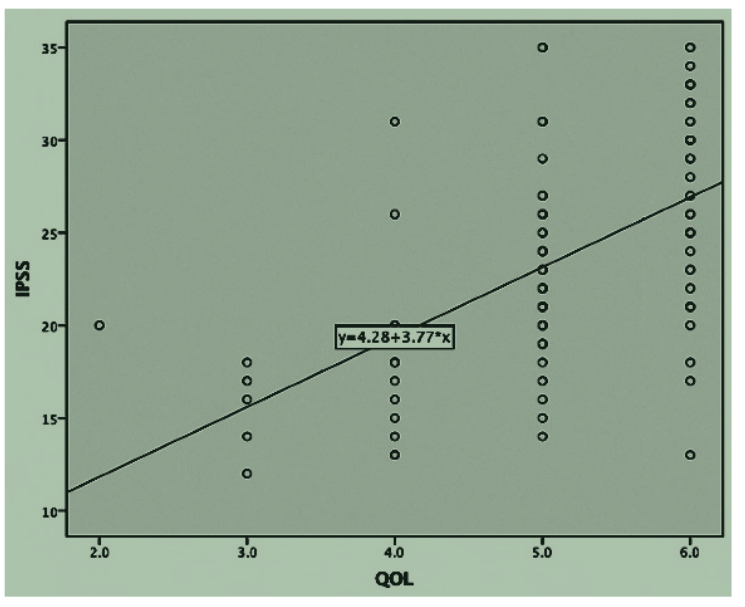

Figure 2. Scatter diagram-showing correlation between IPSS and QOL

Spearman's rho Correlation Coefficient 0.585 (Pvalue $<0.001$ ) 


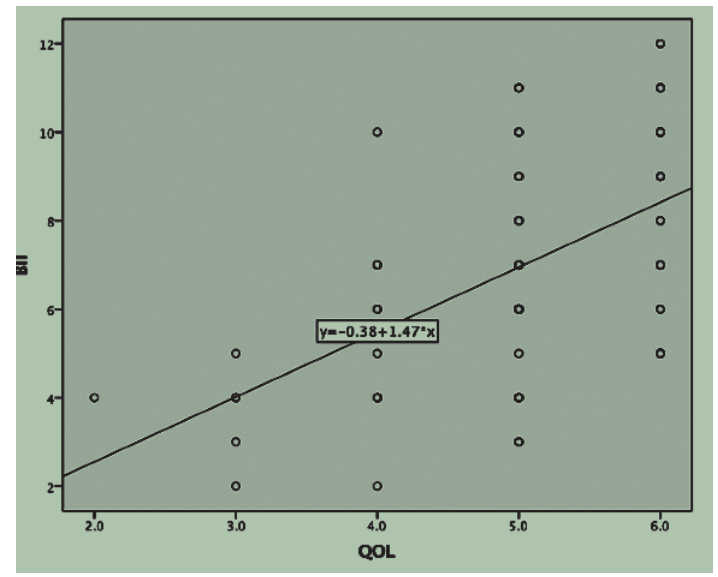

Figure 3. Scatter diagram showing correlation between QOL and BPH II

Spearman's rho Correlation Coefficient 0.530 (P value $<0.001$ )

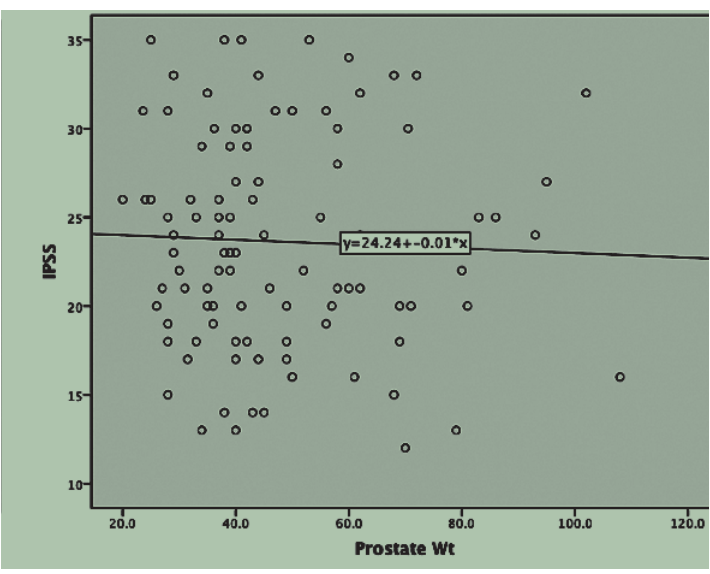

Figure 4. Scatter diagram showing correlation between Prostate Wt and IPSS

Spearman's rho Correlation Coefficient -0.042 (P value 0.68)

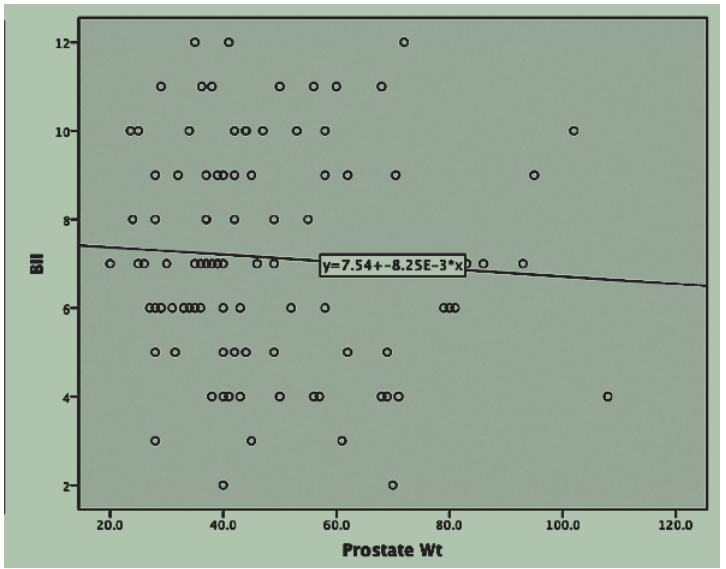

Figure 5. Scatter diagram showing correlation between Wt of Prostate and BPH II
Spearman's rho Correlation Coefficient 0.070 (P value 0.49)

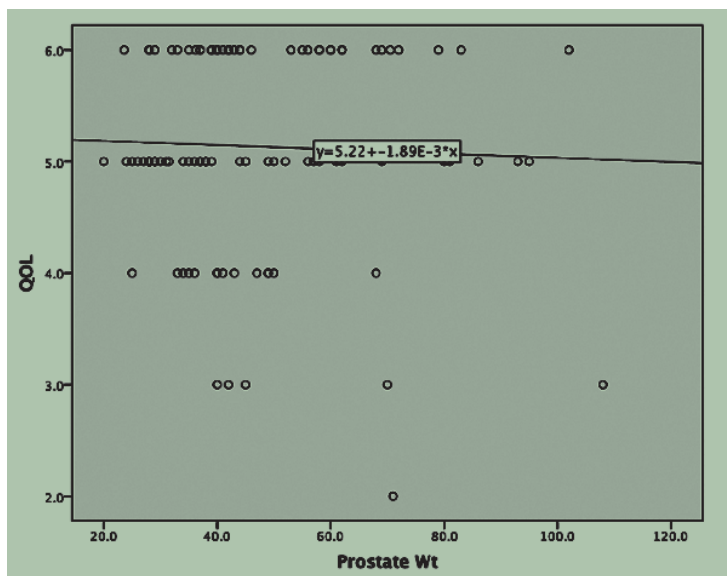

Figure 6. Scatter diagram showing correlation between QOL and Wt of Prostate

Spearman's rho Correlation Coefficient 0.054 (P value 0.59)

The mean IPSS, QOL, BPH II and Prostate Volumes were $23.6 \pm 6.0,5.1 \pm 0.9,7.1 \pm 2.4$ and $47.5 \pm 16.63$ respectively. There was positive correlation between the IPSS \&BPH II, IPSS \& QOL and BPH II \& QOL $\left(\mathrm{r}_{\mathrm{s}}=0.89,0.585\right.$ and 0.530 respectively) and no correlation between IPSS \& Prostatic Wt and BPH II and Prostatic Wt. $\left(\mathrm{r}_{\mathrm{s}}=-0.04\right.$ and -0.07 respectively).

\section{Discussion}

$\mathrm{BPH}$ is a condition related to ageing. ${ }^{4}$ Though it is not life threatening, its clinical manifestation as LUTS reduces the patient's quality of life. ${ }^{5}$ By the age of 60 years, nearly $60 \%$ of the cohort of the Baltimore Longitudinal Study of Aging had some degree of clinical BPH. ${ }^{6}$ Troublesome LUTS can occur in up to $30 \%$ of men older than 65 years. $^{7}$ In the present study, the mean age of the patients was $66.7 \pm$ 7.3 (Range: $50-84$ years) with $>50 \%$ patients were in their sixth decade of life. All of these patients had moderate to severe symptoms. The mean age of patients with moderate to severe symptoms in other various studies are similar to that of the present study. ${ }^{8-10}$

A large body of evidence documents the accuracy of transrectal ultrasound (TRUS) in calculating the volume of the prostate. ${ }^{11,12}$ TRUS has significantly higher accuracy than that of cystoscopy, IVU, rectal examination and or urethral pressure profile. $^{13}$ Studies have reported high degree of correlations between the TAUS and TRUS methods in prostate volume measurements. ${ }^{14,15}$ Hence we used transabdominal ultrasound for evaluation of prostatic 
weight as it is less invasive than TRUS. In the present study, the mean weight of prostate was $47.5 \pm 16.63 \mathrm{~g}$ and furthermore $83.7 \%$ of patients had prostate volumes in excess of $30 \mathrm{gm}$. The mean weight of prostate in studies done at Hong Kong in small group, in India and in another study in Nepalese patients is similar to that of present study. ${ }^{10,16,17}$

The bothersome symptoms and impact of LUTS on QOL is the main reason why men seek treatment for $\mathrm{BPH} .{ }^{18}$ The $\mathrm{BII}$ is a BPH-specific measure that assesses the impact of BPH symptoms on patient health and functioning. ${ }^{19}$ When the primary goal for treating patients with clinical manifestations of BPH is to relieve bothersome symptoms, the BPH II could be used to measure symptom impact on patients.

Varieties of treatment alternatives are available for men diagnosed to have BEP. The main goal of these treatments is to relieve symptoms by relieving obstruction. However, the correlation between symptoms and urodynamically proven obstruction are believed to be weak. ${ }^{9,20}$

The present study has shown a high degree of positive correlation between BII and IPSS, which is comparable to other studies performed in, much larger population in western countries. ${ }^{19,21}$ The higher degree of correlation in this study might be due to higher the degree of symptoms.

The mean IPSS in this study was higher than the mean IPSS in other studies of western population but similar to our part of world. ${ }^{10}$ This could be due to delay in seeking treatment in our part of world.

This study had shown comparable moderate degree of positive correlation between BPH II and QOL when compared with studies done in west as described in table 4. However, mean BII was higher in our study when compared with above mentioned studies which could be due difference in study group. Our study group consisted the patient who were planned for surgical management whereas study population in those studies were being managed medically.

Similar to our study other studies have consistently shown no correlation between prostate size and symptom severities in patients who have a clinical diagnosis of $\mathrm{BPH} .{ }^{10,22}$

Our study has certain limitations. We did not analyze LUTS function through objective measurements such as flow rates in all patients because significant numbers of patients were having per urethral catheter.

\section{Conclusion}

There is positive correlation of IPSS with BII, but no correlation between the prostate size and the symptoms (IPSS, BII). Management of the BPH patients should be considered on the bother symptoms and not on the size of prostate.

\section{References}

1. Berry SJ, Coffey DS, Walsh PC, Ewing LL. The development of human benign prostatic hyperplasia with age. The Journal of urology. 1984;132(3):474-9.

2. Mebust W RRSFVA. Correlations between pathology,clinical symptoms and the course of the disease. . Proceedings of the International Consultation on Benign Prostatic Hyperplasia Geneva: WHO. 1991:51-62.

3. Barry MJ, Fowler FJ, Jr., O’Leary MP, Bruskewitz RC, Holtgrewe HL, Mebust WK. Correlation of the American Urological Association symptom index with self-administered versions of the Madsen-Iversen, Boyarsky and Maine Medical Assessment Program

Table 4. Comparison of studies that assessed the Correlation of BII, IPSS, QOL and Prostatic weight

\begin{tabular}{|c|c|c|c|c|c|}
\hline $\begin{array}{l}\text { Baseline } \\
\text { Characteristics }\end{array}$ & $\begin{array}{l}\text { Present Agrawal et al }{ }^{10} \\
\text { Study }\end{array}$ & Michael et al ${ }^{23}$ & Boyle et al ${ }^{21}$ & Angalakuditi et al ${ }^{19}$ & Ganpule et $\mathbf{a l}^{22}$ \\
\hline \multicolumn{6}{|l|}{ BII Correlation } \\
\hline IPSS & 0.899 & & 0.55 & 0.66 & \\
\hline Prostatic Weight & -0.07 & & & & \\
\hline QOL & 0.53 & 0.68 & & 0.56 & \\
\hline \multicolumn{6}{|c|}{ IPSS Correlation } \\
\hline Prostatic Weight & -0.04 & & & & 0.15 \\
\hline QOL & 0.58 & & & 0.55 & 0.72 \\
\hline
\end{tabular}


symptom indexes. Measurement Committee of the American Urological Association. The Journal of urology. 1992;148(5):1558-63; discussion 64.

4. Chute CG, Panser LA, Girman CJ, Oesterling JE, Guess HA, Jacobsen SJ, et al. The prevalence of prostatism: a population-based survey of urinary symptoms. J Urol. 1993;150(1):85-9.

5. Donovan JL, Kay HE, Peters TJ, Abrams P, Coast $\mathrm{J}$, Matos-Ferreira A, et al. Using the ICSOoL to measure the impact of lower urinary tract symptoms on quality of life: evidence from the ICS-'BPH' Study. International Continence Society--Benign Prostatic Hyperplasia. Br J Urol. 1997;80(5):712-21.

6. Arrighi HM, Metter EJ, Guess HA, Fozzard JL. Natural history of benign prostatic hyperplasia and risk of prostatectomy. The Baltimore Longitudinal Study of Aging. Urology. 1991;38(1 Suppl):4-8.

7. Chapple CR. BHP Disease Management. Introduction and concluding remarks: Eur Urol. 1999;36 Suppl 3:1-6.

8. Kaplan SA, Te AE, Pressler LB, Olsson CA. Transition zone index as a method of assessing benign prostatic hyperplasia: correlation with symptoms, urine flow and detrusor pressure. The Journal of urology. 1995;154(5):1764-9.

9. Lee T, Seong DH, Yoon SM, Ryu JK. Prostate shape and symptom score in benign prostatic hyperplasia. Yonsei medical journal. 2001;42(5):532-8.

10. Agrawal CS, Chalise PR, Bhandari BB. Correlation of prostate volume with international prostate symptom score and quality of life in men with benign prostatic hyperplasia. Nepal Medical College journal : NMCJ. 2008;10(2):104-7.

11. Aarnink RG, Beerlage HP, De La Rosette JJ, Debruyne FM, Wijkstra H. Transrectal ultrasound of the prostate: innovations and future applications. The Journal of urology. 1998;159(5):1568-79.

12. Aarnink RG, De La Rosette JJ, Debruyne FM, Wijkstra $H$. Reproducibility of prostate volume measurements from transrectal ultrasonography by an automated and a manual technique. Br J Urol. 1996;78(2):219-23.

13. Roehrborn CG. Accurate determination of prostate size via digital rectal examination and transrectal ultrasound. Urology. 1998;51(4A Suppl):19-22.
14. Styles RA, Neal DE, Powell PH. Reproducibility of measurement of prostatic volume by ultrasound. Comparison of transrectal and transabdominal methods. European urology. 1988;14(4):266-9.

15. Huang Foen Chung JW, de Vries SH, Raaijmakers R, Postma R, Bosch JL, van Mastrigt R. Prostate volume ultrasonography: the influence of transabdominal versus transrectal approach, device type and operator. European urology. 2004;46(3):352-6.

16. Chen SS, Hong JG, Hsiao YJ, Chang LS. The correlation between clinical outcome and residual prostatic weight ratio after transurethral resection of the prostate for benign prostatic hyperplasia. BJU Int. 2000;85(1):79-82.

17. MC Songra RK. A study on the correlation between clinical outcome and residual prostatic weight ratio after transurethral resection of the prostate for benign prostatic hyperplasia. Indian Journal of urology. 2004;20(2):42-6.

18. AUA guideline on management of benign prostatic hyperplasia (2003). Chapter 1: Diagnosis and treatment recommendations. J Urol. 2003;170(2 Pt 1):530-47.

19. Angalakuditi M, Seifert RF, Hayes RP, O’Leary MP, Viktrup L. Measurement properties of the benign prostatic hyperplasia impact index in tadalafil studies. Health and quality of life outcomes. 2010;8:131.

20. Barry MJ, Cockett AT, Holtgrewe HL, McConnell JD, Sihelnik SA, Winfield HN. Relationship of symptoms of prostatism to commonly used physiological and anatomical measures of the severity of benign prostatic hyperplasia. The Journal of urology. 1993;150(2 Pt 1):351-8.

21. Boyle P, Robertson C, Mazzetta C, Keech M, Hobbs R, Fourcade R, et al. The relationship between lower urinary tract symptoms and health status: the UREPIK study. BJU international. 2003;92(6):575-80.

22. Ganpule AP, Desai MR, Desai MM, Wani KD, Bapat SD. Natural history of lower urinary tract symptoms: preliminary report from a community-based Indian study. BJU international. 2004;94(3):332-4.

23. O'Leary MP, Wei JT, Roehrborn CG, Miner M. Correlation of the International Prostate Symptom Score bother question with the Benign Prostatic Hyperplasia Impact Index in a clinical practice setting. BJU international.2008;101(12)1531-5. 